\title{
Mitteilungen der Schweizerischen Menopausengesellschaft/SMG
}

J. Gynäkol. Endokrinol. 2018 ·21:15

https://doi.org/10.1007/s41975-018-0030-8

(c) Springer-Verlag GmbH Austria, ein Teil von Springer Nature 2018
Präsidentin

Prof. Dr. med. Petra Stute (V.i. S. d.P.)

Administration SMG

Weißdornweg 17

D-35041 Marburg/Lahn

Tel.: +49 (0) 62093444

E-Mail: administration@meno-pause.ch
Liebe Kolleginnen und Kollegen!

Der diesjährige Women's Health Kongress fand am 17.01.2018 und 18.01.2018 in Zürich statt. Die SMG war mit den sehr gut besuchten Sessions „Komplementärmedizin bei Östrogenmangelfolgen nach gynäkologischen Tumoren" und „Frauengesundheit: Du bist, was $\mathrm{Du}$ isst" vertreten.

Erstmalig erfolgte hier die Verleihung des SMG Science Award in Höhe von CHF 1000 an Frau Nada Woodtli, Bern, für die Einreichung ihrer Arbeit „Attitude towards Social Freezing in Swiss women - a cross sectional study“. Zusätzlich zum Preisgeld erhielt die Preisträgerin einen Reisekostenzuschuss sowie freien Eintritt zum Kongress. Herzlichen Glückwunsch!

Der nächste SMG Science Award wird während des 15 . Women's Health Kongress am 10. Januar 2019 in Bern verliehen werden. Details zur Ausschreibung 2019 finden Sie auf der Website der SMG www. meno-pause.ch oder Sie wenden sich an unsere Geschäftsstelle. Wir freuen uns auf Ihre Einreichung!

Während der jährlichen Generalversammlung im Rahmen des 14. Women's Health Kongress am 17.01.2018 berichtete der Vorstand über seine Aktivitäten in 2017:

- Die Satzung wurde dahingehend angepasst, dass im Falle der Auflösung der SMG deren Vermögen an die AGER fällt.

- Der Mitgliederstand hatte sich zum 17.01.2018 mit 28 Neuzugängen und 6 Kündigungen zu gesamt 170 Mitgliedern entwickelt.

- Die Homepage wurde in das Französische übersetzt.

- Der SMG Newsletter wird zweimonatlich per E-Mail an alle Mitglieder versendet.

- Erstmalig wurde der über 1000 CHF dotierte SMG Wissenschaftspreis ausgeschrieben.

- Das SMG/DMG deutschsprachige Symposium während des EMAS Amsterdam 2017 wurde von den Besuchern sehr gut angenommen.

- Während des SGGG Jahreskongresses 2017 in Lau- sanne fand am Donnerstag, 29.06.2017, ein sehr gut besuchter Workshop der SMG/ AGER mit dem Titel „Einsatzmöglichkeiten von Progesteron" statt. Die Moderation erfolgte durch Frau Prof. Dr. med. Petra Stute, Bern, und Frau Dr. Maki Kashiwagi, Uster.

- Je eine Laienveranstaltung wurde in 2017 von Herrn Dr. Niklaus Flütsch sowie von Frau Professor Petra Stute durchgeführt.

Weitere Laienveranstaltungen sind für 2018 in Planung.

Während des SGGG Kongresses 2018 in Interlaken werden der SMG am 27.06.2018 ein Hauptsymposium mit dem Titel „Rund um die Menopause, Quiz the Ex- pert" sowie ein Workshop zur Verfügung stehen. Hierzu laden wir Sie herzlich ein.

Ebenfalls wird sich die SMG aufgrund der erfreulichen Besucherzahlen während des EMAS Kongress Berlin 2019 an einer deutschsprachigen Session beteiligen.

Informationen, u. a. zu einer Mitgliedschaft oder zum SMG Science Award, erhalten Sie von: Administration Schweizerische Menopausengesellschaft - SMGAnne Becker

Weißdornweg 17 35041 Marburg/Lahn, Deutschland

Tel.: 0049 (0)642093444

E-Mail: administration@menopause.ch

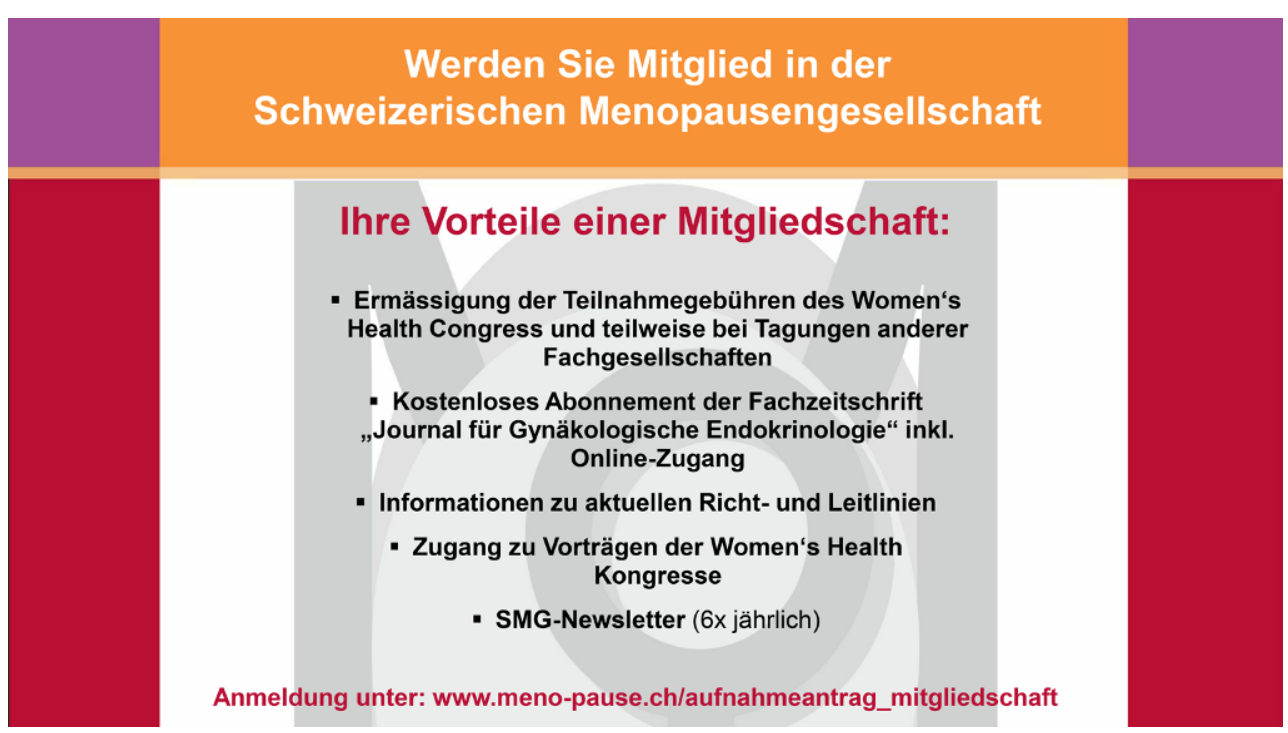

